Note

\title{
Comparison of Different Temperature Conditions for Microbial Enumeration of Aspergillus brasiliensis in the Preservative Efficacy Test
}

\author{
JUN USUKURA* \\ Fundamental Research Institute Division, MANDOM Corp. 5-12 Juniken-cho, Chuo-ku, Osaka 540-8530, Japan \\ Received 30 April, 2020/Accepted 3 August, 2020
}

\begin{abstract}
The preservative efficacy test is an important method for assessing the antimicrobial effect of cosmetic products. In this study, the optimum conditions for the efficient microbial enumeration of Aspergillus brasiliensis were investigated. Cosmetic products, inoculated with $A$. brasiliensis spore suspensions, were cultivated at $22.5^{\circ} \mathrm{C}, 32.5^{\circ} \mathrm{C}$, or $40^{\circ} \mathrm{C}$ and the detection rate and the number of colonies were determined using the pour culture method. There was no difference in the viable counts of visible colonies among different temperature conditions. However, the viable counts after 3 days of culture were significantly greater for the cultures maintained at $32.5^{\circ} \mathrm{C}$ or $40^{\circ} \mathrm{C}$ compared with those maintained at $22.5^{\circ} \mathrm{C}$. This effect was attenuated in products containing fatty acids, which could inhibit fungal growth. Overall, these results demonstrate that cultivating $A$. brasiliensis at $32.5^{\circ} \mathrm{C}$ reduces the time required for enumeration in the preservative efficacy test. Thus, the results of this study are expected to help improve and expedite microbiological quality control in the cosmetic industry.
\end{abstract}

Key words : Aspergillus brasiliensis / Cosmetics / Preservative efficacy test.

Inadequate microbial control of cosmetic products can lead to quality deterioration or health problems, especially since several types of cosmetics are used multiple times (Devilieghere et al., 2015, Dawson and Reinhardt, 1981). The preservative efficacy test, ISO11930 (International Organization for Standardization, 2012) and the Japan pharmacopoeia (2016) are important methods for measuring the antimicrobial effect of cosmetic products.

As a fungal strain, Aspergillus brasiliensis is mainly cultured under the same general conditions with fungi, based on the ISO11930 or Japan pharmacopoeia guidelines, with an incubation period of 3-5 days at $22.5 \pm 2.5^{\circ} \mathrm{C}$ or 5 days at $25^{\circ} \mathrm{C}$, respectively. However, the optimum growth temperature for the genus Aspergillus is typically greater than $30^{\circ} \mathrm{C}$ (Takatori, 1991). Moreover, the optimum growth temperature of A. niger, which was previously classified as the same species as A. brasiliensis (Ja'nos et al., 1991), is $33^{\circ} \mathrm{C}$

*Corresponding author. Tel: +81-6-6767-5034, Fax: +81-66767-5047, E-mail : jun.usukura(a)mandom.com with an upper limit of $42^{\circ} \mathrm{C}$ (Takatori, 1991). Koide and Yosokawa (2008) reported that the growth rate of colonies and spores of $A$. niger increase as the culture temperature is raised to $30^{\circ} \mathrm{C}$, after which the growth rate is maintained up to $35^{\circ} \mathrm{C}$. Based on this background, it can be hypothesized that there is a difference between the optimum growth temperature and actual culture conditions of $A$. brasiliensis currently used in the preservative efficacy test, which can influence the results.

Therefore, in this study, the optimal culture conditions for microbial enumeration in the preservative efficacy test was investigated using $A$. brasiliensis.

Aspergillus brasiliensis NBRC9455 was purchased from the National Institute of Technology and Evaluation, cryopreserved, and used as the test microbe. Ten kinds of cosmetic products were used in the preservative efficacy test with $A$. brasiliensis, which are presented in Table 2. Facial wash products contain 4 to 32 fatty acids, including a combination of lauric acid and myristic acid and/or palmitic acid and/or stearic acid. The spores of $A$. brasiliensis were cultured on potato dextrose agar until they reached the appropriate abundance. 
TABLE 1. Culture temperatures of Aspergillus species ${ }^{3}$ ).

\begin{tabular}{|c|c|c|c|c|}
\hline \multirow{2}{*}{ Genus } & \multirow{2}{*}{ Species } & \multicolumn{3}{|c|}{ Culture temperature $\left({ }^{\circ} \mathrm{C}\right)$} \\
\hline & & Lower limit & Optimum & Upper limit \\
\hline Aspergillus & clavatus & 8 & 30 & 38 \\
\hline & flavus & 8 & 35 & 42 \\
\hline & fumigatus & 10 & 37 & 52 \\
\hline & niger & 5 & 33 & 42 \\
\hline & restrictus & 6 & 30 & 37 \\
\hline
\end{tabular}

TABLE 2. Test specimens.

\begin{tabular}{|c|c|c|}
\hline Product category & $n=$ & Addition \\
\hline Facial wash & 3 & acid \\
\hline Body wash & 1 & caterogy \\
\hline Lotion & $\frac{3}{2}$ & Other \\
\hline
\end{tabular}
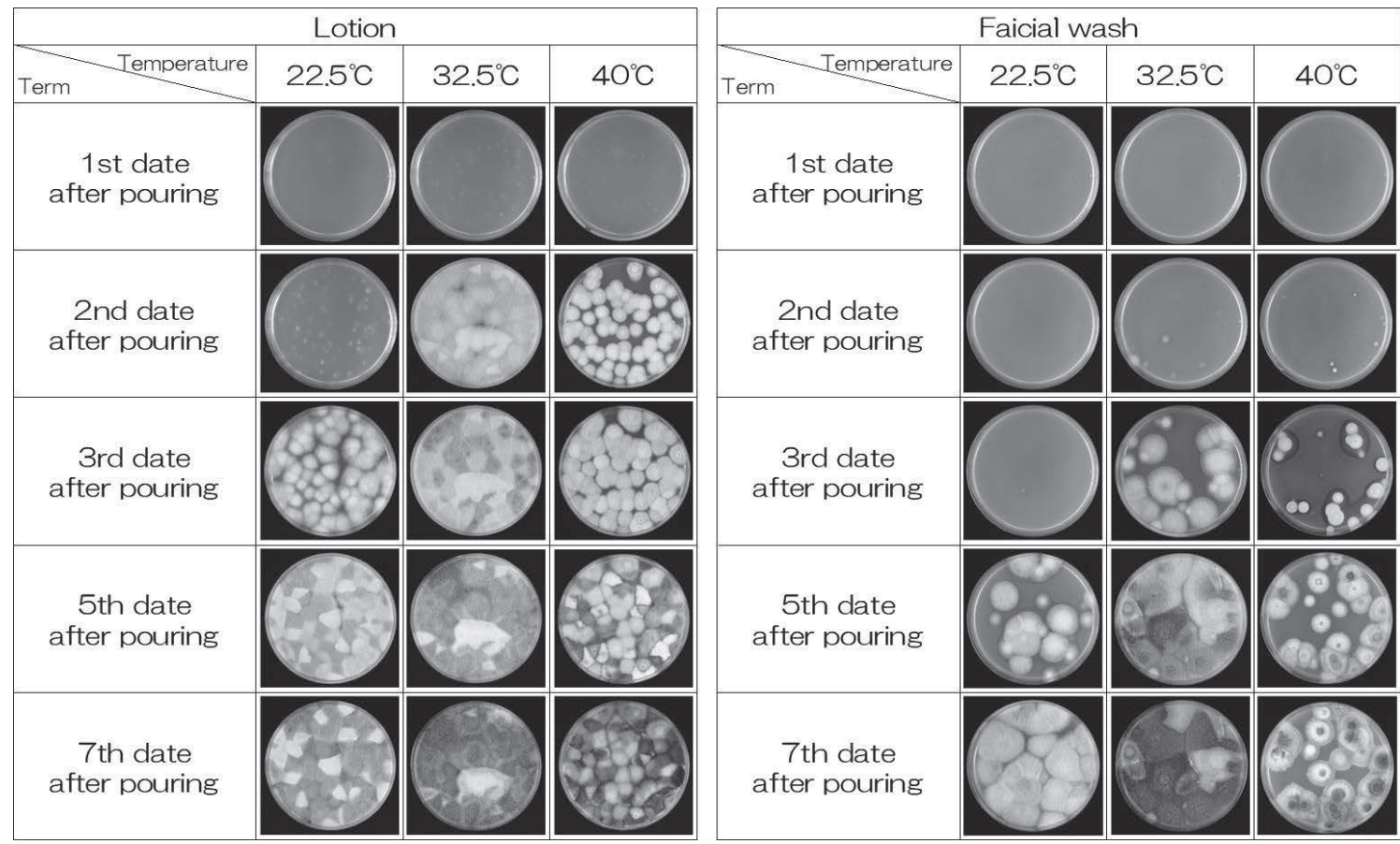

FIG. 1. Appearance of $A$. brasiliensiscolonies on days 1-7 after pour culture. Left:lotion on day 21 after inoculation; right: facial wash on day 7 after inoculation.

The spores were then collected with a cotton bar and placed in a saline solution containing 2\% Tween 80 and $10^{6}$ cells $/ \mathrm{mL}$, and filtered using sterilized gauze. Each cosmetic product, about $20 \mathrm{~g}$, was weighed in a glass container and then inoculated with the prepared spore solution at a concentration of approximately $10^{4}$ $\mathrm{cfu} / \mathrm{g}$. The microbial enumeration of each sample was determined on days 7,14 , and 21 of storage at $22.5^{\circ} \mathrm{C}$. Microbial enumeration was conducted by pouring 1 $\mathrm{g}$ or $1 \mathrm{~mL}$ of the specimen into glucose peptone agar medium, containing lecithin and polysorbate. Microbial enumeration was calculated by counting the number of colonies on day $1,2,3,5$, or 7 after pouring the culture at $22.5^{\circ} \mathrm{C}$, as the conventional test condition, or under $32.5^{\circ} \mathrm{C}$ and $40^{\circ} \mathrm{C}$ as the potentially improved condition.

Representative examples of typical plates for the lotion cultured under each temperature condition on day 21 (or day 7 for the facial wash) after $A$. brasiliensis spore suspension inoculation are shown in Fig. 1. At $22.5^{\circ} \mathrm{C}$, the conventional condition for culturing $A$. brasiliensis, small colonies were visible on the plate by day 2 for the lotion and day 3 for the facial wash, which became more clearly visible by the next day. At $32.5^{\circ} \mathrm{C}$ or $40^{\circ} \mathrm{C}$, the colonies tended to form about 1 day earlier than at $22.5^{\circ} \mathrm{C}$. However, the colonies that were formed at $40^{\circ} \mathrm{C}$ tended to be smaller than those at $22.5^{\circ} \mathrm{C}$ or $32.5^{\circ} \mathrm{C}$. Based on a previous report showing that $A$. brasiliensis colonies cannot grow bigger when cultured at temperatures above $30^{\circ} \mathrm{C}$ (Koide and Yosokawa, 1991), we predicted that culturing at a higher temperature than the typical conditions might reduce the colony size owing to growth inhibition.

However, there were no significant differences in the viable counts calculated from day 7 after pour culture was performed under each temperature condition. These results suggested that temperature influenced the 


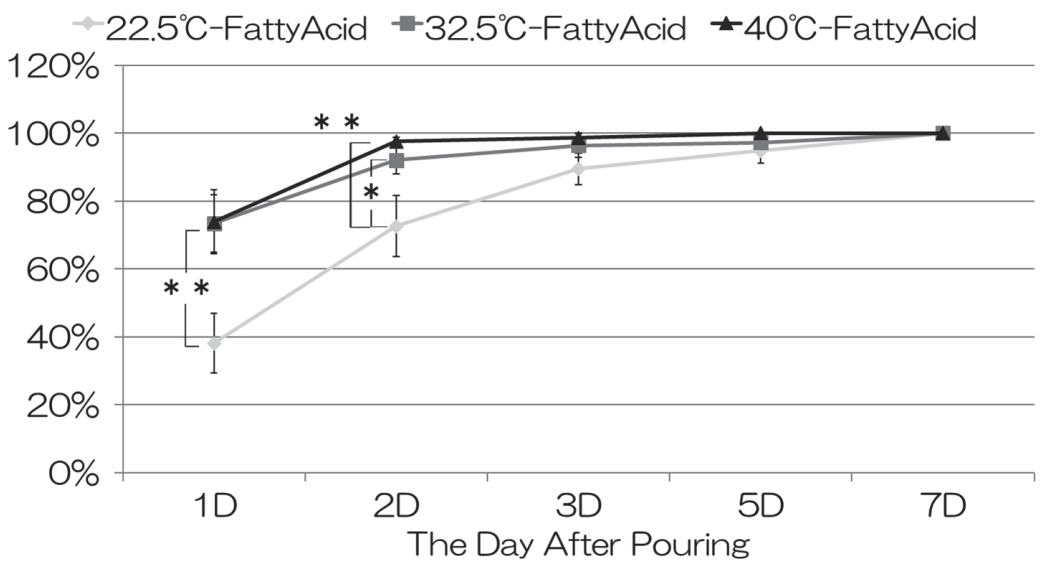

FIG. 2. Detection rates of $A$. brasiliensisin fatty acid-containing products on day 7 after culture in each temperature condition $\left(: 22.5^{\circ} \mathrm{C}, \square: 32.5^{\circ} \mathrm{C}, \boldsymbol{\Delta}: 40^{\circ} \mathrm{C}\right)$. Vertical axis shows detection rate which is calculated from the following formula (viable count determined on each cultivating date) / (viable count determined on day 7$) .{ }^{* *}: p<0.05,{ }^{*}: p<0.10$

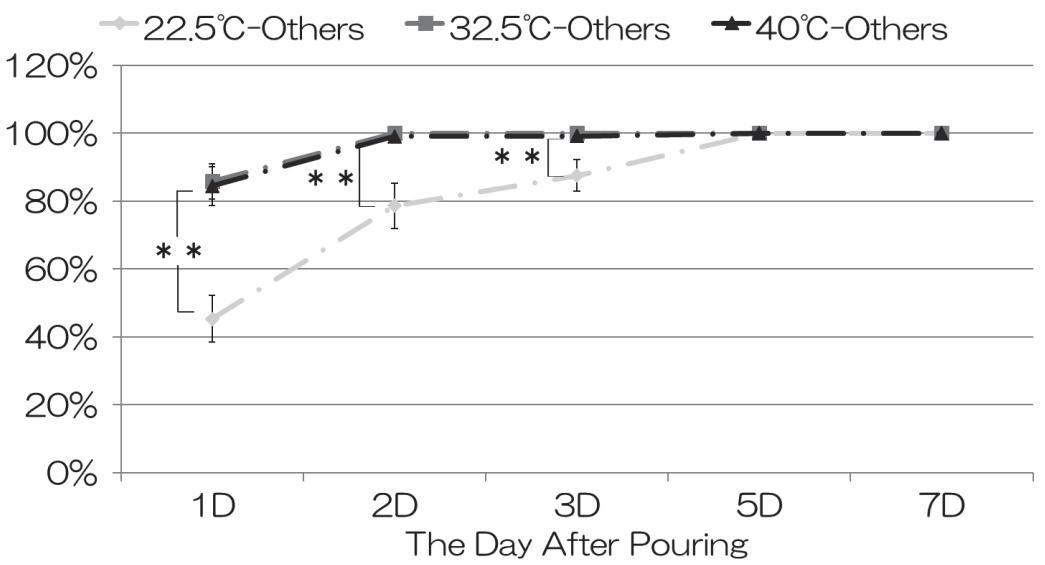

FIG. 3. Detection rate of $A$. brasiliensisin products without fatty acids (Others) on day 7 after culture in each temperature condition $\left(: 22.5^{\circ} \mathrm{C}, \square: 32.5^{\circ} \mathrm{C}, \boldsymbol{\Delta}\right.$ : $40^{\circ} \mathrm{C}$ ). Vertical axis shows detection rate which is calculated from the following formula (viable count determined on each cultivating date) / (viable count determined on day 7 ). ${ }^{\star *}: \mathrm{p}<0.05$

growth rate of colonies, but not the viable counts, based on the final number of the colonies.

The colony detection rates under each condition were calculated using the following formula: viable counts determined on each cultivating date/viable counts determined on day 7 . The products containing fatty acid soap were distinguishable from other products with an evident delay in colony growth due to the inhibitory effect of fatty acids on microbial growth (Fig. 2, 3). Compared with cultures maintained at $22.5^{\circ} \mathrm{C}$, the detection rate on each cultivating date was greater for cultures maintained at $32.5^{\circ} \mathrm{C}$ in all product categories. On day 2 of culture, the colony detection rates under high-temperature conditions $\left(32.5^{\circ} \mathrm{C}\right.$ or $\left.40^{\circ} \mathrm{C}\right)$ were greater than $90 \%$, whereas those at $22.5^{\circ} \mathrm{C}$ were less than $80 \%$. In particular, the detection rate on day 3 of culture in the "other" products category (i.e., not fatty acids), significantly differed between $22.5^{\circ} \mathrm{C}$ and $32.5^{\circ} \mathrm{C}$ or $40^{\circ} \mathrm{C}$ culture conditions $(p<0.05)$. These results suggested that the cultivating temperature could 
increase the colony detection rate of $A$. brasiliensis. In addition, the growth rate at $40^{\circ} \mathrm{C}$ was higher than that at $22.5^{\circ} \mathrm{C}$, suggesting that high temperature inhibited the colony size while promoting germination or growth (Fig. 2 and Fig. 3).

Overall, these results confirmed that the number of days to achieve visible detection of colony formation in all cosmetic product categories could be shortened by culturing at higher temperatures, such as $32.5^{\circ} \mathrm{C}$ or $40^{\circ} \mathrm{C}$. Additionally, the final viable counts determined under high-temperature conditions on day 7 after inoculation were equivalent to those detected at the conventional culture temperature of $25^{\circ} \mathrm{C}$.

These results suggest that microbial enumeration at $32.5^{\circ} \mathrm{C}$ may be the most suitable condition for determining the viable counts more rapidly when conducting the preservative efficacy test of $A$. brasiliensis. The results of this study can efficiently shorten microbiological quality control, thereby contributing to expediting the development of cosmetic products.

\section{REFERENCES}

Dawson, N. L., and Reinhardt, D. J. (1981) Microbial flora of in-use, display eye shadow testers and bacterial challenges of unused eye shadows. Appl. Environ. Microbiol., 42(2), 297-302.

Devilieghere,F., De Loy-Hendrickx, A., Rademarker, P. M., Pipelers, Crozier, A., De Beats, B., Joly, L. and Keromen, S. (2015) A new protocol for evaluating the efficacy of some dispensing systems of a packaging in the microbial protection of water-based preservatives-free cosmetic products. Int. J. Cosmet. Sci., 37, 627-635.

International Organization for Standardization. (2012) ISO 11930. Cosmetics - Microbiology - Evaluation of the antimicrobial protection of a cosmetic product.

Ja'nos, V., Sa'ndor, K., Be a'ta, T., Jens, C.F.,Giancarlo, P., Antonia, S., Martin, M. and Robert, A. S. (2007) Aspergillus brasiliensis sp. nov., a biseriate black Aspergillus species with world-wide distribution. IJSEM, 57, 1925-1932.

Japanese Pharmacopoeia, Seventeenth Edition. (2016) JP17. 2499-2501.

Koide, S., and Yasokawa, D. (2008) Growth prediction of mycelial mat and fruiting zone diameters of Aspergillus niger subjected to temperature changes (in Japanese). Nippon. Shokuhin Kagaku Kogaku Kaishi, 55 (7), 338-344.

Takatori, K. (1991) Hitome de wakaru zusetsu kabi kensa. sousa manual (in Japanese). pp. 20-21. TECHNO SYSTEM, Tokyo. 